\title{
Nowe stanowiska i historia odkrycia Saxifraga paniculata (Saxifragaceae) na Wyżynie Krakowsko-Częstochowskiej
}

Trzy nowe stanowiska Saxifraga paniculata Mill. (skalnicy gronkowej) zostały znalezione w paśmie Skał Kroczyckich na Wyżynie Częstochowskiej. Największe znajduje się na północnej i wschodniej ścianie skały Jastrzębnik (Ryc. 1A) w masywie Góry Łysak, na wysokości 20-40 metrów powyżej podstawy ściany. Obserwacja prowadzona z użyciem lornetki pozwoliła dostrzec cztery płaty o szacunkowej łącznej powierzchni około $20 \mathrm{~m}^{2}$ oraz liczne rozproszone różyczki skalnicy gronkowej. Dokładna ocena wielkości populacji i ewentualny zbiór roślin do zielnika nie były możliwe. Kilkanaście płonnych różyczek S. paniculata rośnie także na zacienionej skałce u wschodniego podnóża Jastrzębnika.

Drugie mniejsze stanowisko znajduje się na skale Wysoki Okap (Ryc. 1B) w masywie Góry Łysak. Skalnica gronkowa rośnie na północnej i zachodniej ścianie, na wysokości 10-20 metrów i jest równie niedostępna.

Trzecie stanowisko Saxifraga paniculata znajduje się na szczycie skały Bogdanka (Ryc. 1C) w masywie Popielowej Góry i składa się z kilku niewielkich płatów i pojedynczych różyczek rozproszonych na trudno dostępnej grani.

$\mathrm{Na}$ wszystkich znalezionych stanowiskach razem z Saxifraga paniculata rosną m.in.: Allium senescens subsp. montanum (Pohl) Holub, Asplenium trichomanes L., Carex pallidula Harmaja, Cotoneaster integerrimus Medik., Festuca pallens Host, Hepatica nobilis Mill., Hieracium bifidum Horenm., Juniperus communis L., Libanotis montana Crantz, Polygala amara subsp. brachyptera (Chodat) Hayek, Polygonatum odoratum (Mill.) Druce, Polypodium vulgare L., Sempervivum soboliferum Sims, Valeriana tripteris L. i Vincetoxicum hirundinaria Medik.

Dotychczas w paśmie Skał Kroczyckich znane było jedno stanowisko skalnicy gronkowej na szczycie Popielowej Góry (Ryc. 1D) odkryte przez Mróz i MAJCHRZAK (2003), które udało mi się potwierdzić.

W Polsce skalnica gronkowa reprezentowana jest przez kilka taksonów wewnątrzgatunkowych (STASzKIEWICZ \& WósCicki 1978). Rośliny występujące na Wyżynie KrakowskoCzęstochowskiej należą do Saxifraga paniculata var. maior (Koch) H. Huber.

Saxifraga paniculata jest rośliną górską (SzAFER 1930). W Polsce jest częsta tylko w Tatrach i Pieninach (ZAJAc \& ZAJĄC 2001). Jej nieliczne reliktowe stanowiska na Wyżynie Krakowsko-Częstochowskiej są zagrożone a część z nich zanikła. Największym zagrożeniem dla jurajskich populacji skalnicy gronkowej jest nasilający się ruch turystyczny, zwłaszcza niczym nieograniczona wspinaczka skałkowa prowadzona także w rezerwatach przyrody. Problem ten dotyczy również wszystkich stanowisk gatunku w paśmie Skał Kroczyckich. Utworzenie obszaru chronionego Natura 2000 Ostoja Kroczycka nie stanowi wystarczającego zabezpieczenia dla flory tego cennego obszaru, podobnie jak działalność Centrum dziedzictwa przyrodniczego i kulturowego Jury w Podlesicach, która polega głównie na autopromocji, pobieraniu opłat za wstęp do rezerwatu Góra Zborów, a nawet reklamowaniu prywatnych szkół wspinaczki skałkowej działających w okolicy. Dlatego postuluje pilne wprowadzenie zakazu wspinaczki na skałach, na których rośnie skalnica gronkowa. 

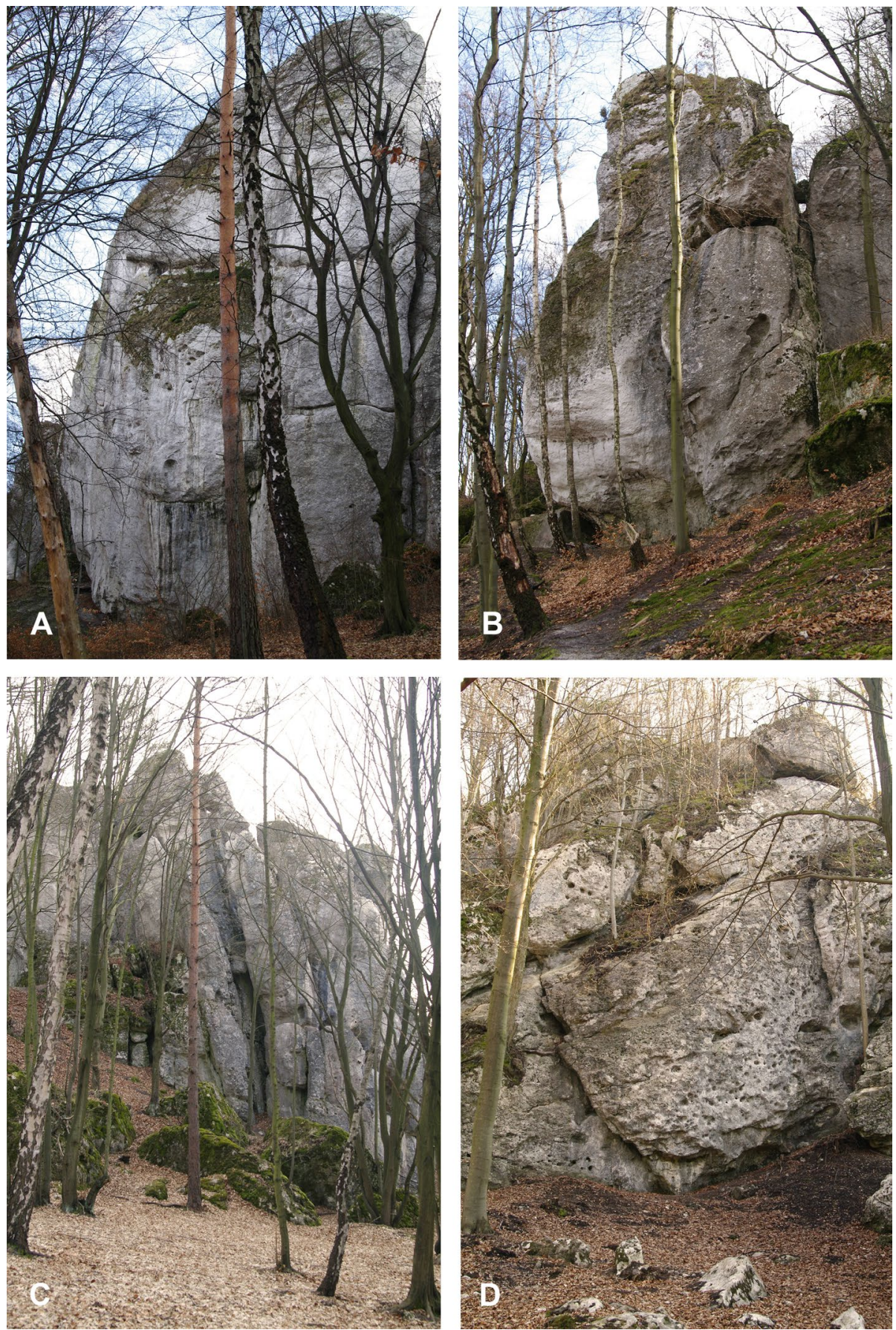

Ryc. 1. Stanowiska Saxifraga paniculata w paśmie Skał Kroczyckich: A - skała Jastrzębnik, B - skała Wysoki Okap, C - skała Bogdanka, D - skała Popielowa Góra (fot. Z. Szeląg, 2020)

Fig. 1. Localities of Saxifraga paniculata in the Skały Kroczyckie hills: A - Jastrzębnik rock, B - Wysoki Okap rock, C - Bogdanka rock, D - Popielowa Góra rock (photo by Z. Szelagg, 2020) 
Występowanie Saxifraga paniculata na Wyżynie Krakowsko-Częstochowskiej ograniczone jest do czterech rejonów, które odwiedziłem w 2019 r. w celu uaktualnienia danych. Największa populacja znajduje się w Olsztynie na Górze Zamkowej i kilku sąsiednich ostańcach. Dosyć duża populacja utrzymuje się w Dolinie Będkowskiej, gdzie jednak obserwuje się znaczny spadek liczebności w ostatnim trzydziestoleciu. Niewielkie i najbardziej zagrożone są populacje w paśmie Skał Kroczyckich oraz w Podzamczu w sąsiedztwie zamku Ogrodzieniec. Od ponad stu pięćdziesięciu lat niepotwierdzone pozostaje stanowisko S. paniculata w Ojcowie.

Saxifraga paniculata na Wyżynie Krakowsko-Częstochowskiej odkrył profesor Wojciech Jastrzębowski w 1847 r. w Olsztynie (ŚwIERZYŃSKI 1848). Kolejne doniesienie o występowaniu gatunku 'na skałach Olsztyńskich' znajduje się w Sprawozdaniu z podróży naturalistów odbytej w r. 1854 do Ojcowa (STRONCZYŃSKI i in. 1855). W 1856 r. S. paniculata w Olsztynie znalazł Ferdynand KARO (1881) i zebrane okazy przesłał do Juliusa Milde do Wrocławia. Ten, pisząc o występowaniu gatunku 'Auf den benachbarten nidrigen Hügeln von weissem Jurakalk bei Czenstochau', nie wspomniał o Karo, sobie przypisując odkrycie (MILDE 1862). W XIX w. o S. paniculata w Olsztynie pisali także WIślicKi i LöWENHARD (1856), BERDAU (1859a) oraz SAPALSKI (1862).

Pierwsza informacja o występowaniu Saxifraga paniculata w Ojcowie na Górze Zamkowej została podana przez Wiślickiego i Löwenharda (1856). Publikacja ta składa się z dwóch części, które ukazały się w kolejnych numerach pierwszego tomu czasopisma Przyroda i Przemyst. Część pierwsza znajduje się w numerze 15. i traktuje m.in. o stanowisku S. paniculata w Olsztynie, natomiast część druga, zawierająca doniesienia z Ojcowa, znajduje się w numerze 16. i została przeoczona przez wszystkich kolejnych badaczy. Pierwszym był BERDAU (1859b), który wyraził opinię o kilku gatunkach podanych przez Wiślickiego i Löwenharda z okolic Olsztyna i Złotego Potoku, jednak nie wspomniał o odkryciach dokonanych przez nich w Ojcowie. W 1867 r. F. Karo zebrał S. paniculata w Ojcowie lecz ogłosił to dopiero w 1881 r. (KARO 1881). Wcześniej, korzystając z zielnika Karo, stanowisko opublikował RosTAFIŃSKI (1872), który, podobnie jak Berdau, nie cytuje drugiej część publikacji WIŚLICKIEGO i LöWENHARDA (1856). Również ELENKIN (1901) odkrycie S. paniculata w Ojcowie przypisał F. Karo. MichaliK (1978) wymienił S. paniculata z Ojcowa za RostAFIŃSKIM (1872) ale uznał, że 'data ta odnosi się niewątpliwie do stanowiska w Dolinie Będkowskiej'. Uważam ten wniosek za nieuprawniony. Po pierwsze, Rostafí́ski (1872) nie wspomina o stanowisku S. paniculata w Dolinie Będkowskiej ponieważ zostało ono odkryte dopiero dwadzieścia lat później (BŁoŃsKI 1892). Po drugie, wydaje się mało prawdopodobne, aby tak skrupulatny w pracy terenowej badacz jak F. Karo pomylił Dolinę Będkowską z Ojcowem. Po trzecie, KARO (1881) zaznacza, że w Ojcowie $S$. paniculata 'przytrafia się rzadko', podczas gdy w Dolinie Będkowskiej 'spotkać ją można na każdym prawie kroku' (WóYcicki 1913b), 'całe zbocza pokrywa' (KozŁowsKa 1923), rośnie 'w ogromnej obfitości' (PAwŁowsKi 1924) i nawet wiele lat później spotykana jest 'bardzo często' (KosIŃsKi 1992). I wreszcie, jest zapomniana publikacja WIŚLICKIEGO i LöWENHARDA (1856), która ukazała się 11 lat przed wizytą Karo w Ojcowie.

Saxifraga paniculata w ‘Bentkowicach’ odkrył Franciszek BŁOŃSKI (1892). W kolejnych latach o skalnicy gronkowej w Dolinie Będkowskiej pisali ELENKIN (1901), 
Wóycicki (1913a, b), KozŁowska (1923), PAwŁowski (1924) oraz KosińsKi (1992), który przedstawił mapę jej rozmieszczenia. Obserwacje, które przeprowadziłem w 2019 r. w Dolinie Będkowskiej, wykazały znaczne spadek liczby stanowisk gatunku w porównaniu z danymi KosińsKIEGo (1992). Nie odnalazłem m.in. stanowiska na skale Zamczysko (Dupa Słonia).

W Podzamczu Saxifraga paniculata została znaleziona w 1995 r. na bezimiennym ostańcu położonym około 300 m na północny-zachód od ruin zamku Ogrodzieniec (SzELĄG 2000). Przez kolejne dwadzieścia lat liczebność populacji utrzymywała się na stałym poziomie. Ostatnio jednak rośliny są niszczone, ponieważ w bezpośrednim ich sąsiedztwie prowadzona jest nauka wspinaczki.

Stanowisko Saxifraga paniculata na 'Jankowej Górze za Podlesicami w Kroczycach' odkrył Kazimierz KAZNOwsKi (1922). Nazwa 'Jankowa Góra' nie jest obecnie używana i nie udało mi się ustalić, o które wzniesienie chodzi. Mając na uwadze, że Kaznowski wyruszał w teren z Zawiercia (KAZNOwski 1928), lokalizacja 'za Podlesicami' może odpowiadać Pośredniej Górze lub Popielowej Górze w paśmie Skał Kroczyckich. Pomiędzy tymi wzniesieniami wiodła droga z Podlesic na północ, okrążająca od wschodu Berkową Górę (MAPA 1934). Być może Jankowa Góra to dzisiejsza Pośrednia, nazywana także Jamkową, w masywie której znajduje się skała Jamkowa Baszta. Równie prawdopodobne wydaje się, że KAZNOwsKi (1922) mógł pisać o obecnej Popielowej Górze, gdzie utrzymuje się niewielka populacja $S$. paniculata znaleziona przez Mróz i MAJCHRZAK (2003). Nie można także wykluczyć, że przed stu laty $S$. paniculata miała szerszy zasięg i rosła na obu wzgórzach.

Podsumowując, w paśmie Skał Kroczyckich znajdują się obecnie cztery stanowiska Saxifraga paniculata: na Bogdance i Popielowej w masywie Popielowej Góry oraz na Jastrzębniku i Wysokim Okapie w masywie Góry Łysak.

Summary. New localities and history of the discovery of Saxifraga paniculata (Saxifragaceae) in the Wyżyna Krakowsko-Częstochowska Upland. In May 2018, three new populations of Saxifraga paniculata Mill. were found in the Skały Kroczyckie hills in the Wyżyna Krakowsko-Częstochowska Upland (Fig. 1). In Poland, S. paniculata is frequent only in the Tatra Mts and Pieniny Mts in the Western Carpathians; its occurrence in the Wyżyna Krakowsko-Częstochowska Upland consists of relict populations from the Pleistocene glacial (Vistulian).

In the Wyżyna Krakowsko-Częstochowska Upland, Saxifraga paniculata occurs in four regions: the Dolina Będkowska valley, Olsztyn village, Podzamcze village and Skały Kroczyckie hills. The oldest locality was found in the Olsztyn village by Professor Wojciech Jastrzębowski in 1847. The locality in the Ojców village has not been confirmed for more than 150 years. All populations of S. paniculata in the Wyżyna Krakowsko-Częstochowska Upland are strongly endangered due to intensive tourism and rock climbing.

\section{LITERATURA}

BERDAU F. 1859a. Przegląd flory okolic Krakowa. - Rocznik Cesarsko-Królewskiego Towarzystwa Naukowego Krakowskiego 26: 213-658 + tab. I.

Berdau F. 1859b. Kilka słów o roślinności i florze Ojcowa, jako dodatek do flory Królestwa Polskiego. - Biblioteka Warszawska. Pismo poświęcone naukom, sztukom i przemysłowi 7: 496-511. 
BŁoŃSKI F. 1892. Przyczynek do flory jawnokwiatowej oraz skrytokwiatowej naczyniowej kilkunastu okolic kraju. - Pamiętnik Fizyograficzny 12(3): 129-149.

ELEnKIN A. A. 1901. Flora Ojtsovskoj doliny. s. 167 + tab. II. Sovet Imperatorskogo Varšavskogo Universiteta, Varšava.

Karo F. 1881. Flora okolic Częstochowy. - Pamiętnik Fizyograficzny 1: 208-257.

KAZNOWSKI K. 1922. Przyczynek do flory okolic Zawiercia i Wyżyny Kielecko-Sandomierskiej. - Kosmos. Czasopismo Polskiego Towarzystwa Przyrodników im. Kopernika 47(1-3): 101-104.

KAZNOWSKI K. 1928. Rośliny naczyniowe okolic Zawiercia. - Sprawozdanie Komisji Fizjograficznej 62: 185-207.

KosiŃsKi M. 1992. Flora naczyniowa skał, muraw i zarośli kserotermicznych Doliny Będkowskiej. - Prądnik. Prace i materiały muzeum im. prof. Władysława Szafera 5: 109-148.

KozŁowsKa A. 1923. Stosunki geobotaniczne Ziemi Miechowskiej. - Sprawozdanie Komisji Fizjograficznej 57: 1-68 + Mapa.

MAPA. 1934. Kroczyce 46/29H 1:25000, Sokolniki 46/29E 1:25000 - Wojskowy Instytut Geograficzny, Warszawa.

MichaLiK S. 1978. Rośliny naczyniowe Ojcowskiego Parku Narodowego. - Studia Naturae, Seria A 16: $1-171$.

MiLdE J. 1862. Die Verbreitung der schlesischen Laubmoose nach den Höhen und ihre Bedeutung für die Beurtheilung der schlesischen Flora. - Novorum Actorum Academiae Caesareae Leopoldino-Carolinae Germanicae Naturae Curiosorum 29: 1-48.

Mróz E. \& MajchrzaK B. 2003. Materiały do flory roślin naczyniowych Skał Kroczyckich (Wyżyna Częstochowska). - Fragmenta Floristica et Geobotanica Polonica 10: 3-11.

PAwŁowski B. 1924. Osobliwości roślinnej szaty Ojcowa i postulaty jej ochrony. - Ochrona Przyrody 4: $75-82$.

RostAFIŃsKI J. 1872. Florae Polonicae Prodromus. Uebersicht der bis jetzt im Königreiche Polen beobachteten Phanerogamen. - Verhandlungen der kaiserlich-königlichen zoologisch-botanischen Gesellschaft in Wien 22: 81-208.

SAPALSKI J. 1862. Pogląd na historyą naturalną Gubernii Radomskiej. s. 110 + tab. I. E. Kołakowski, Kielce.

StaszKiewicz J. \& WósCicki J. J. 1978. Zmienność klonów Saxifraga paniculata Miller (S. aizoon Jacq.) z kilku stanowisk w Polsce. - Fragmenta Floristica et Geobotanica 24: 3-21.

STRONCZYŃSKI K., TACZANOWSKI W. \& WAGA A. 1855. Sprawozdanie z podróży naturalistów odbytej w r. 1854 do Ojcowa. - Biblioteka Warszawska. Pismo poświęcone naukom, sztukom i przemysłowi 58: $142-172,355-379$.

SzAFER W. 1930. Element górski we florze niżu polskiego. - Rozprawy Wydziału Matematyczno-Przyrodniczego, Polska Akademia Umiejętności 69, Seria 3, Dział B: 83-196.

SzELĄG Z. 2000. Materiały do flory Wyżyny Krakowsko-Częstochowskiej. - Fragmenta Floristica et Geobotanica Polonica 7: 93-103.

ŚWIERZYŃSKI K. 1848. Opis podróży po kraju, odbytej przez 12 uczniów Instytutu Agronomicznego w Marymoncie, pod przewodnictwem profesora Wojciecha Jastrzębowskiego, w czasie wakacyj, to jest w miesiącach lipcu i sierpniu 1847. - Biblioteka Warszawska. Pismo poświęcone naukom, sztukom i przemysłowi 29: 33-92.

WiśLICKI A. \& LöWENHARD S. 1856. Wędrówka po olkuskim powiecie, pod względem naukowym, gospodarskim oraz przemysłowo-fabrycznym. - Przyroda i Przemysł 1(15): 117-122, 1(16): 125-132.

WóYcicki Z. 1913a. Roślinność Ojcowa. - Obrazy roślinności Królestwa Polskiego 5: 1-40 + tab. X. 
WóYCicki Z. 1913b. Roślinność Ojcowa. - Obrazy roślinności Królestwa Polskiego 6: 1-26 + tab. X.

ZAJĄC A. \& ZAJĄC M. (red.). 2001. Atlas rozmieszczenia roślin naczyniowych w Polsce. s. xii + 714. Pracownia Chorologii Komputerowej, Instytut Botaniki, Uniwersytet Jagielloński, Kraków.

ZBIGNIEw Szelą, Instytut Biologii, Uniwersytet Pedagogiczny w Krakowie, ul. Podchorażych 2, 30-084 Kraków, Polska; e-mail: azszelag@wp.pl

Wptynęto: 22.03.2020 r.; przyjęto do druku: 30.09.2020 r.

DOI: https://doi.org/10.35535/ffgp-2020-0047

\section{Oenothera flaemingina (Onagraceae) - nowy gatunek we florze Krakowa}

W Polsce występuje obecnie ponad 30 gatunków wiesiołków (Oenothera) (Rostański \& TOKARSKA-GUZIK 1998; RosTAŃSKI i in. 2010) o zróżnicowanym zasięgu i częstości występowania. Jednym z nich jest Oenothera flaemingina Hudziok, wiesiołek flemingski, który należy do grupy gatunków rzadziej odnotowywanych w naszym kraju. Oenothera flaemingina został opisany przez Hudzioka z terenu Niemiec (HudzIOK 1968), jednakże jego pochodzenie nie zostało dotychczas ostatecznie wyjaśnione. Jest to gatunek mieszańcowy, powstały najprawdopodobniej na skutek skrzyżowania się O. rubricaulis i $O$. jueterbogensis (RostAŃSKI i in. 2010). Jednakże pod względem morfologicznym O. flaemingina jest najbardziej zbliżony do O. acutifolia Rostański (Rostański \& WiTosŁAwsKi 2003), co sprawia, że często jest on nieprawidłowo oznaczany. Głównymi cechami wyróżniającymi $O$. flaemingina są: ciemnoczerwona łodyga i oś kwiatostanu, ciemnozielone liście oraz cienkie koniuszki działek (HudZIOK 1968; RosTAŃsKi \& WiTOSŁAWSKI 1998).

Oenothera flaemingina, podobnie jak pozostałe gatunki wiesiołków, występuje najczęściej w siedliskach zaburzonych, głównie na podłożu piaszczystym, często na terenach uprzemysłowionych tj. w pobliżu torów kolejowych, dróg oraz na nieużytkach (RostAŃSKI \& WiTOSŁAWSKI 2003). W Europie gatunek ten został dotychczas zaobserwowany i potwierdzony tylko na terenie Niemiec oraz Polski (Rostański i in. 2010). Pierwsze stanowiska w naszym kraju odnotowali w swojej pracy RosTAŃsKi \& WiToSŁAWSKI (1998). Większość ze znanych dotychczas stanowisk Oenothera flaemingina zlokalizowana jest na terenach przemysłowych województwa łódzkiego, małopolskiego, śląskiego i świętokrzyskiego. Poza tym obserwowany był również na pojedynczych stanowiskach w województwie podlaskim i pomorskim (ROSTAŃSKI \& WiTOSŁAWSKI 1998; ZAJAC \& ZAJĄC 2001). Ze względu na rosnącą liczbę notowań przypuszcza się, że gatunek ten może w najbliższym czasie rozprzestrzeniać się na kolejne obszary Polski (RosTAŃSKI \& WiTOSŁAWSKI 2003).

Opisywane nowe stanowisko Oenothera flaemingina zostało odnalezione w sierpniu 2019 r. w Krakowie, w pobliżu Alei gen. T. Bora-Komorowskiego, na terenie nieużytku $\left(50^{\circ} 05^{\prime \prime} 08,5^{\prime \prime} \mathrm{N}, 19^{\circ} 58^{\prime} 50,2^{\prime \prime} \mathrm{E}\right)$. Stosując metodę kartogramu ATPOL ustalono, że stanowisko 